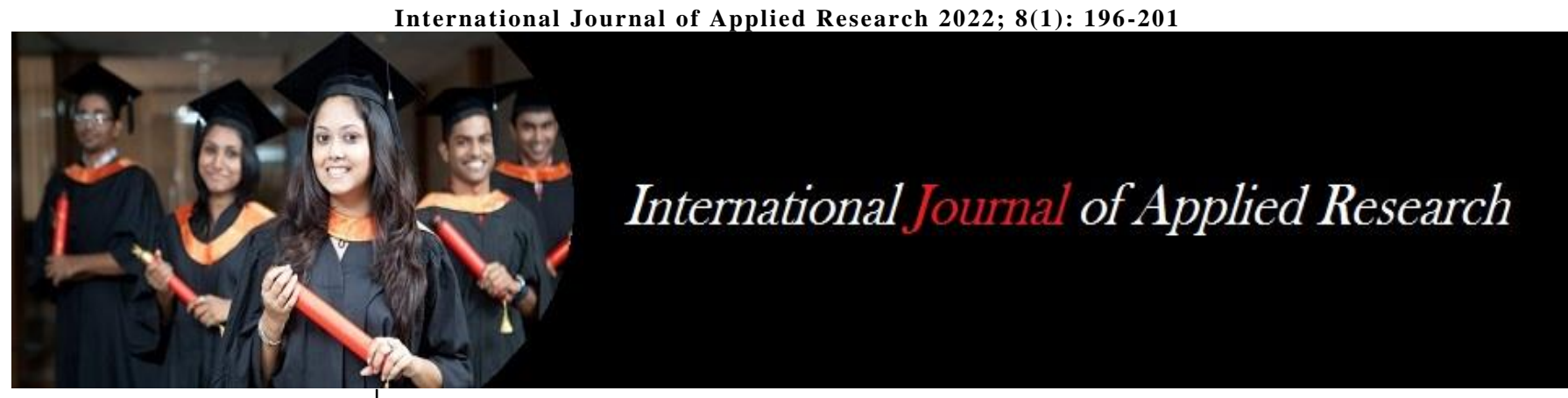

ISSN Print: 2394-7500

ISSN Online: 2394-5869

Impact Factor: 8.4

IJAR 2022; 8(1): 196-201

www.allresearchjournal.com

Received: 24-10-2021

Accepted: 09-12-2021

Rajaiah E

Department of Botany,

University College of Science.

Saifabad. Osmania University,

Hyderabad, Telangana, India

Nageswara Rao Singisala Department of Botany,

University College of Science.

Saifabad. Osmania University,

Hyderabad, Telangana, India
Corresponding Author:

Nageswara Rao Singisala

Department of Botany,

University College of Science.

Saifabad. Osmania University,

Hyderabad, Telangana, India

\section{Medicinal plants with antioxidant potential of leaf extracts of selected medicinal plants}

\section{Rajaiah E and Nageswara Rao Singisala}

DOI: https://doi.org/10.22271/allresearch.2022.v8.i1d.9336

\section{Abstract}

Traditional system of medicine is a part of Indian life. The present study was carried out to know the anti oxidant activity of selected medicinal plants viz, Aegle marmelos, Butea monosperma, Comnifora wighti, Holostemma ada-kodien, Decalepis hamiltonii, Gloriosa superba, Gymnema sylvestre and Santalum album were studied from Indalwai forest of Nizamabad. DPPH, Nitric Oxide, Superoxide, Hydrogen peroxide scavenging activity of methanol leaf extracts at different concentrations were studied (ascorbic acid used as standard). The present study revealed the anti oxidant activity of the leaf extracts of selected plants at all concentrations tested.

Keywords: Anti oxidant, Aegle marmelos, Gloriosa superba, Gymnema sylvestre and Santalum album, Ascorbic acid

\section{Introduction}

Ayurveda is the oldest and offers a holistic approach and it is popular in practice since the Vedic period. Medicinal plants are connecting links between the traditional (Homeopathic) and modern (Allopathy) systems. In India traditional system almost runs parallel to the modern medicine health care providers. Government of India officially recognized and established AYUSH ministry.

Since time immemorial, medicinal plants have been exploited for their medicinal use. Nature has been the source a large number curative compounds in addition to the resources. The use of ancient traditional medicine is a part of the people in the third world countries. There is an ever increasing demand for extraction, isolation, purification and development of drugs for chemotherapy from traditional medicinal plants. (UNESCO, 1998) ${ }^{[1]}$.

The phytochemicals in medicinal plants are responsible for the activities like antioxidant, antimicrobial and antipyretic (Cowman, 1999; Adesokan et al., 2008) ${ }^{[2,3]}$. As per W.H.O, plants are life saving as they are sources of drugs and should be screened for their safety and efficacy (Nascimento et al., 2000) ${ }^{[4]}$. Evidences suggest that humans might have employed the pharmacological properties of plants and their parts to treat the diseases since the inception of civilization. The phenolic and flavonoids are antioxidant and aids in free radical scavenging activity along with anti-inflammatory and anti cancerous in nature (Asha et al. 2011) ${ }^{[8]}$.

Antioxidants scavenge free radicals, and convert reactive oxygen species, antioxidant nature is due to phytochemicals. As of late developing proof has been collected demonstrating the contribution of reactive oxygen species (ROS) in the pathogenesis of numerous sicknesses (Halliwell et al., 1992). These ROS significantly targets lipids, proteins, catalysts, RNA and DNA, brought about unsettling influences of redox balance in a solid body and therefore causes degenerative/oxidative sicknesses, like cardiovascular infections, malignant growth, neuro-degenerative malady and so forth (Ames et al., 1993) ${ }^{[6]}$.

Deepa Babu et al., (2013) ${ }^{[7]}$ have assessed the antioxidant activity of the ethanolic extract of "Triphala". Polyphenols in Triphala exerts anti oxidant activity. The flavonoids, saponins and tannins may be dependable to some extent for the observed pain relieving and calming impact. The utilization of medicinal plants is wide spread internationally and it's increasing day by day and due to the advantages of traditional medicine and its outreach it was planned to study the anti oxidant nature of Aegle marmelos, Butea monosperma, Commifora wighti, 
Holostemma ada-kodien, Decalepis hamiltonii, Gloriosa superba, Gymnema sylvestre and Santalum album leaf extracts.

\section{Materials and Methods \\ DPPH radical scavenging activity}

The total anti-oxidant potential was determined by BrandWilliams et al., and Parejo et al., Various concentrations of test sample were prepared by serial dilution and $0.1 \mathrm{~mL}$ of each dilution was added to $3.9 \mathrm{~mL}$ of a $6.0 \times 10^{-5} \mu \mathrm{M}$ methanol solution of DPPH, followed by vortexing. The reaction was allowed to take place in the dark at room temperature to reach a plateau.

The decrease in the absorbance was measured at $517 \mathrm{~nm}$ was determined by using a Shimadzu spectrophotometer. The concentration of remaining DPPH in the reaction medium was calculated from the calibration curve as follows:

Scavenging effect $(\%)=\frac{(1-\text { A Sample }(517 \mathrm{~nm})}{\text { A Control }(517 \mathrm{~nm})} \mathrm{X} 100$

\section{Super oxide free radical scavenging activity}

Different concentrations of 50, 100, and150 $\mu \mathrm{g} / \mathrm{mL}(10,20$, $30 \mu \mathrm{L})$ of plant extracts were taken and the volume was made up to $150 \mu \mathrm{L}$ with methanol, to each of this, $100 \mu \mathrm{L}$ of riboflavin, $200 \mu \mathrm{L}$ EDTA, $200 \mu \mathrm{L}$ methanol and $100 \mu \mathrm{L}$ NBT was mixed in test tubes and further diluted up to $3 \mathrm{~mL}$ with phosphate buffer and absorbance was measured after illumination for $5 \mathrm{~min}$, at $590 \mathrm{~nm}$ on $\mathrm{UV}$ visible spectrophotometer (Shimadzu, UV-1601), Japan and results were compared with ascorbic acid $(10 \mu \mathrm{g} / \mathrm{mL}$ as standard).

\section{Scavenging of nitric oxide}

Sodium nitroprusside $(5 \mu \mathrm{M})$ in standard phosphate buffer solution was incubated with different concentration of the test extracts dissolved in standard phosphate buffer $(0.025$ $\mathrm{M}, \mathrm{pH} 7.4$ ) and the tubes were incubated at $25^{\circ} \mathrm{C}$ for $5 \mathrm{~h}$. After $5 \mathrm{~h}, 0.5 \mathrm{~mL}$ of incubation solution was removed and diluted with $0.5 \mathrm{~mL}$ Griess reagent (prepared by mixing equal volume of $1 \%$ sulphanilamide in $2 \%$ phosphoric acid and $0.1 \%$ naphthyl ethylene di amine dihydro chloride in water). The absorbance of chromophore formed was recorded at $546 \mathrm{~nm}$.

The control experiment was also carried out in similar manner, using distilled water in the place of extracts. The activity was compared with ascorbic acid.

\section{Scavenging of hydrogen peroxide}

A solution of hydrogen peroxide $(20 \mathrm{mM})$ was prepared in phosphate buffered saline (PBS, pH 7.4). Various concentrations of $1 \mathrm{~mL}$ of the extracts or standards in methanol were added to $2 \mathrm{~mL}$ of hydrogen peroxide solutions in PBS. The absorbance was measured at $230 \mathrm{~nm}$, after 10 min against a blank solution that contained extracts in PBS without hydrogen peroxide. $\mathrm{IC}_{50}$ value is the concentration of the sample required to scavenge $50 \%$ free radical.

The percentage inhibition was calculated by using the following formula.

$$
\text { Scavenging activity }(\%)=\frac{\text { OD of control }-O D \text { sample }}{\text { OD of control }} \times 100
$$

\section{Results and Discussion}

The present study, DPPH scavenging activity revealed the leaf extracts of Aegle marmelos, Butea monosperma, Commifora wighti, Holostemma ada-kodien, Decalepis hamiltonii, Gloriosa superba, Gymnema sylvestre, Santalum album possesses scavenging activity at the studied concentrations.

Pairing of unpaired electrons results in neutralization and converts it into 1-1 di phenyl-2- picryl hydrazine and becomes colorless from purple color.

The DPPH radical was measured at $517 \mathrm{~nm}$. DPPH, Superoxide, Nitric oxide, Hydrogen Peroxide scavenging activity of Aegle marmelos, Butea monosperma, Commifora wighti, Holostemma ada-kodien, Decalepis hamiltonii, Gloriosa superba, Gymnema sylvestre and Santalum album methanol leaf extracts at different concentrations measured [ascorbic acid $(10 \mu \mathrm{g} / \mathrm{ml})$ was used as standard]. The present study revealed that the Aegle marmelos, Butea monosperma, Commifora wighti, Holostemma ada-kodien, Decalepis hamiltonii, Gloriosa superba, Gymnema sylvestre and Santalum album methanol leaf extracts were observed for significant reduction of the super oxide anions and they inhibited the formation of formazan.

It interacts with $\mathrm{O}_{2}$ and results in nitrites and peroxy nitrites formation. Sodium nitroprusside at an optimum $\mathrm{pH}$ results in nitric oxide formation and it reacts with $\mathrm{O}_{2}$ and forms nitrate ions, they are quantitatively measured by use of Greiss reagent. The leaf extracts of selected plants were potent scavengers of nitric oxide and subsequently competes with oxygen (to inhibit the production of nitric oxide). $\mathrm{H}_{2} \mathrm{O}_{2}$ oxidizes thiol (-SH) groups and inactivates some enzymes. The cytotoxicity of $\mathrm{H}_{2} \mathrm{O}_{2}$ is due to hydroxyl radical generated by $\mathrm{H}_{2} \mathrm{O}_{2}$ interaction with $\mathrm{Fe}^{+2}$ and $\mathrm{Cu}^{+2}$ in the cell. Methanol leaf extracts were noticed for significant inhibitory activity of $\mathrm{H}_{2} \mathrm{O}_{2}$ due to the antioxidant and free scavenging of radical activity (Table no's 1-8 and Figure no's 1-8).

Table 1: Anti oxidant activity of Aegle marmelos (All values in this table represent the mean \pm SD $(n=6)$ )

\begin{tabular}{|c|c|c|c|c|}
\hline Aegle Marmelos & Extract 50 $\boldsymbol{\mu g} / \mathbf{m l}$ & Extract 100 $\boldsymbol{\mu g} / \mathbf{m l}$ & Extract 150 $\boldsymbol{\mu g} / \mathbf{m l}$ & Standard 10 $\boldsymbol{\mu g} / \mathbf{m l}$ \\
\hline DPPH & $68 \pm 0.17$ & $75 \pm 0.18$ & $82 \pm 0.59$ & $92 \pm 0.05$ \\
\hline Superoxide & $38 \pm 0.19$ & $43 \pm 0.84$ & $52 \pm 0.71$ & $68 \pm 0.11$ \\
\hline Nitric Oxide & $66 \pm 0.14$ & $68 \pm 0.21$ & $70 \pm 0.32$ & $80 \pm 0.14$ \\
\hline Hydrogen Peroxide & $37 \pm 0.22$ & $41 \pm 0.41$ & $51 \pm 0.71$ & $67 \pm 0.16$ \\
\hline
\end{tabular}




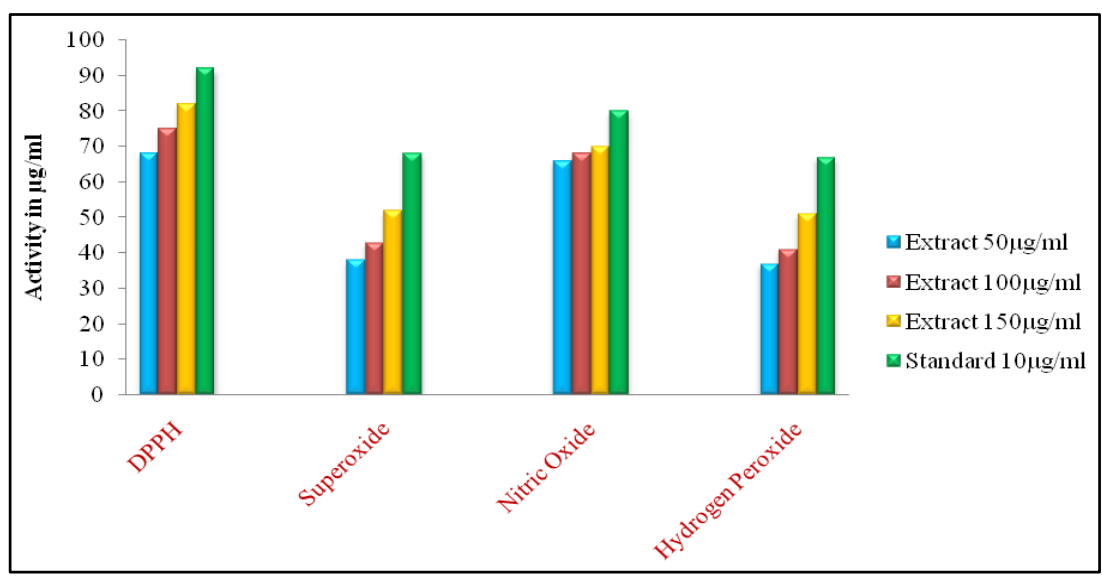

Fig 1: Anti oxidant activity of Aegle marmelos

Table 2: Anti oxidant activity of Butea monosperma. (All values in this table represent the mean $\pm \mathrm{SD}(\mathrm{n}=6)$ )

\begin{tabular}{|c|c|c|c|c|}
\hline Butea monosperma & Extract 50 $\boldsymbol{\mu g} / \mathbf{m l}$ & Extract 100 $\boldsymbol{\mu g} / \mathbf{m l}$ & Extract 150 $\boldsymbol{\mu g} / \mathbf{m l}$ & Standard 10 $\boldsymbol{\mu g} / \mathbf{m l}$ \\
\hline DPPH & $62 \pm 0.21$ & $73 \pm 0.11$ & $80 \pm 0.49$ & $92 \pm 0.16$ \\
\hline Superoxide & $37 \pm 0.14$ & $41 \pm 0.33$ & $50 \pm 0.48$ & $68 \pm 0.19$ \\
\hline Nitric Oxide & $65 \pm 0.21$ & $67 \pm 0.18$ & $69 \pm 0.52$ & $80 \pm 0.14$ \\
\hline Hydrogen Peroxide & $36 \pm 0.31$ & $41 \pm 0.19$ & $50 \pm 0.61$ & $67 \pm 0.13$ \\
\hline
\end{tabular}

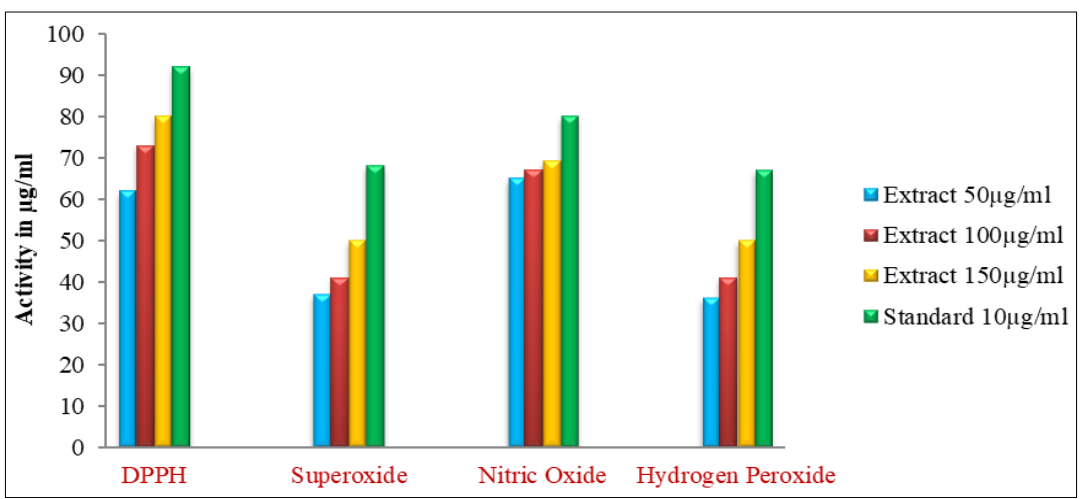

Fig 2: Anti oxidant activity of Butea monosperma

Table 3: Anti oxidant activity of Comnifora wighti (All values in this table represent the mean \pm SD ( $n=6$ )

\begin{tabular}{|c|c|c|c|c|}
\hline Comnifora wighti & Extract 50 $\boldsymbol{\mu g} / \mathbf{m l}$ & Extract 100 $\boldsymbol{\mu g} / \mathbf{m l}$ & Extract 150 $\boldsymbol{\mu g} / \mathbf{m l}$ & Standard 10 $\boldsymbol{\mu g} / \mathbf{m l}$ \\
\hline DPPH & $63 \pm 0.14$ & $74 \pm 0.41$ & $81 \pm 0.16$ & $92 \pm 0.11$ \\
\hline Superoxide & $38 \pm 0.18$ & $40 \pm 0.43$ & $51 \pm 0.17$ & $68 \pm 0.12$ \\
\hline Nitric Oxide & $66 \pm 0.19$ & $67 \pm 0.49$ & $70 \pm 0.12$ & $80 \pm 0.13$ \\
\hline Hydrogen Peroxide & $37 \pm 0.41$ & $42 \pm 0.47$ & $51 \pm 0.13$ & $67 \pm 0.16$ \\
\hline
\end{tabular}

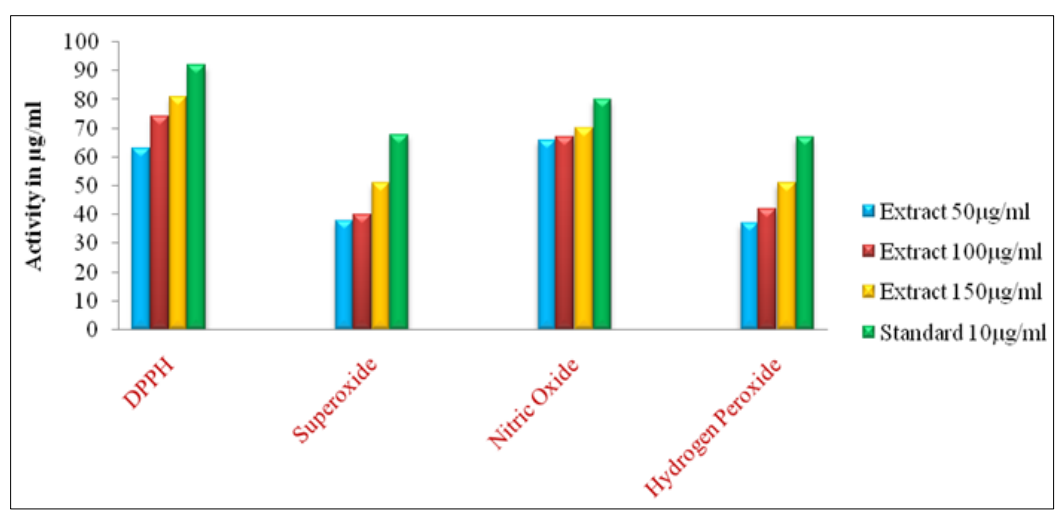

Fig 3: Anti oxidant activity of Comnifora wighti

Table 4: Anti oxidant activity of Holostemma ada-kodien [All values in this table represent the mean \pm SD ( $\mathrm{n}=6$ )]

\begin{tabular}{|c|c|c|c|c|}
\hline Holostemma ada-kodien & Extract 50 $\boldsymbol{\mu g} / \mathbf{m l}$ & Extract 100 $\mathbf{\mu g} / \mathbf{m l}$ & Extract 150 $\boldsymbol{\mu g} / \mathbf{m l}$ & Standard 10 $\boldsymbol{\mu g} / \mathbf{m l}$ \\
\hline DPPH & $60 \pm 0.17$ & $70 \pm 0.39$ & $80 \pm 0.41$ & $92 \pm 0.04$ \\
\hline Superoxide & $40 \pm 0.16$ & $40 \pm 0.33$ & $50 \pm 0.44$ & $68 \pm 0.12$ \\
\hline Nitric Oxide & $60 \pm 0.21$ & $65 \pm 0.34$ & $70 \pm 0.35$ & $80 \pm 0.16$ \\
\hline Hydrogen Peroxide & $35 \pm 0.26$ & $35 \pm 0.31$ & $50 \pm 0.34$ & $67 \pm 0.12$ \\
\hline
\end{tabular}




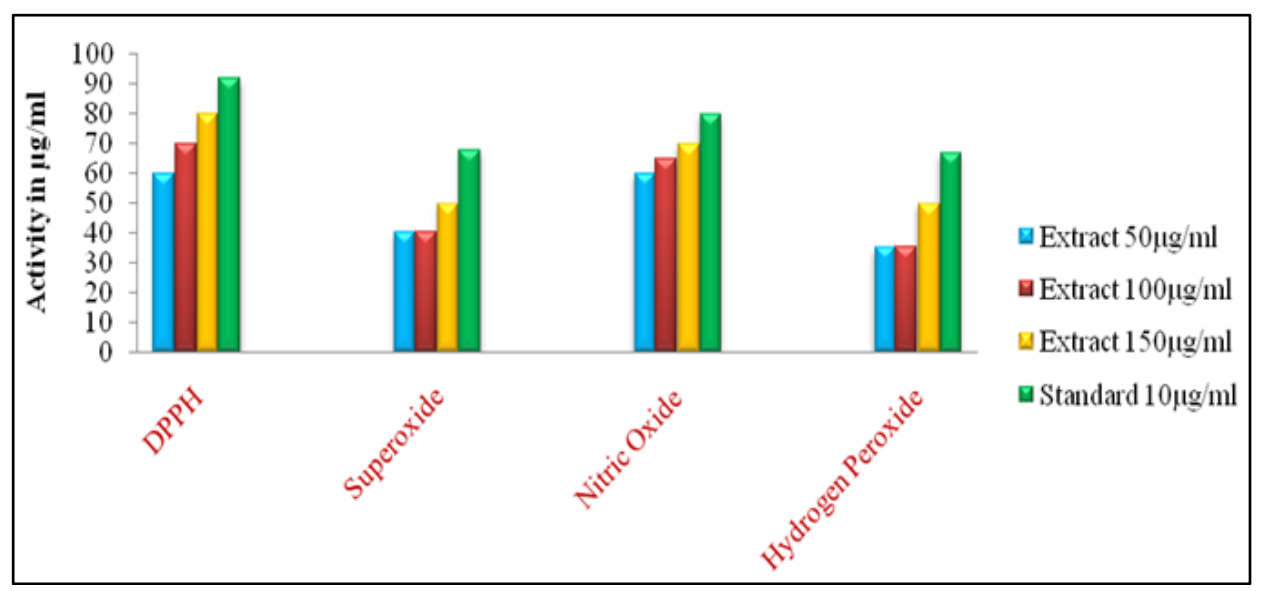

Fig 4: Anti oxidant activity of Holostemma ada-kodien

Table 5: Anti oxidant activity of Decalepis hamiltonii [All values in this table represent the mean \pm SD ( $\mathrm{n}=6$ )]

\begin{tabular}{|c|c|c|c|c|}
\hline Decalepis hamiltonii & Extract 50 $\boldsymbol{\mu g} / \mathbf{m l}$ & Extract 100 $\boldsymbol{\mu g} / \mathbf{m l}$ & Extract 150 $\boldsymbol{\mu g} / \mathbf{m l}$ & Standard 10 $\boldsymbol{\mu g} / \mathbf{m l}$ \\
\hline DPPH & $65 \pm 0.21$ & $75 \pm 0.31$ & $85 \pm 0.17$ & $92 \pm 0.12$ \\
\hline Superoxide & $44 \pm 0.28$ & $44 \pm 0.33$ & $55 \pm 0.54$ & $68 \pm 0.18$ \\
\hline Nitric Oxide & $66 \pm 0.29$ & $71 \pm .38$ & $75 \pm 0.24$ & $80 \pm 0.10$ \\
\hline Hydrogen Peroxide & $38 \pm 0.24$ & $40 \pm 0.23$ & $58 \pm 0.26$ & $67 \pm 0.13$ \\
\hline
\end{tabular}

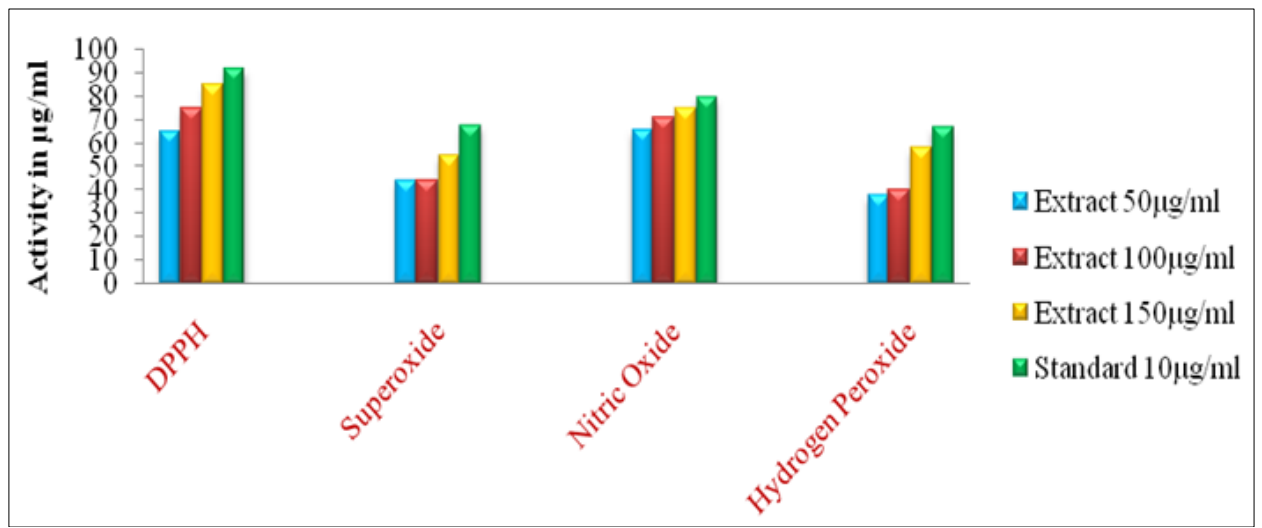

Fig 5: Anti oxidant activity of Decalepis hamiltonii

Table 6: Anti oxidant activity of Gloriosa superba (All values in this table represent the mean \pm SD ( $n=6$ )

\begin{tabular}{|c|c|c|c|c|}
\hline Gloriosa superba & Extract 50 $\boldsymbol{\mu g} / \mathbf{m l}$ & Extract 100 $\boldsymbol{\mu g} / \mathbf{m l}$ & Extract 150 $\boldsymbol{\mu g} / \mathbf{m l}$ & Standard 10 $\boldsymbol{\mu g} / \mathbf{m l}$ \\
\hline DPPH & $66 \pm 0.25$ & $76 \pm 0.16$ & $86 \pm 0.24$ & $92 \pm 0.11$ \\
\hline Superoxide & $45 \pm 0.21$ & $45 \pm 0.21$ & $56 \pm 0.21$ & $68 \pm 0.14$ \\
\hline Nitric Oxide & $67 \pm 0.22$ & $72 \pm 0.18$ & $76 \pm 0.24$ & $80 \pm 0.16$ \\
\hline Hydrogen Peroxide & $39 \pm 0.19$ & $41 \pm 0.17$ & $59 \pm 0.19$ & $67 \pm 0.10$ \\
\hline
\end{tabular}

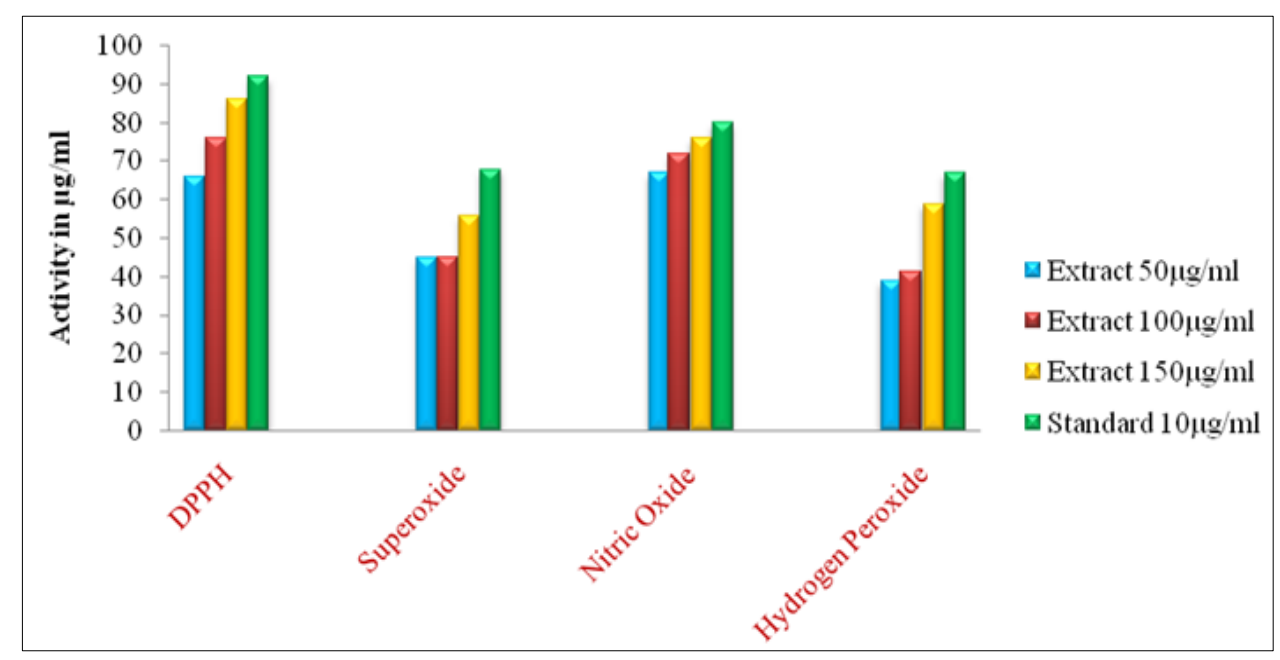

Fig 6: Anti oxidant activity of Gloriosa superba 
Table 7: Anti oxidant activity of Gymnema sylvestre (All values in this table represent the mean \pm SD ( $n=6$ )

\begin{tabular}{|c|c|c|c|c|}
\hline Gymnema sylvestre & Extract 50 $\boldsymbol{\mu g} / \mathbf{m l}$ & Extract 100 $\boldsymbol{\mu g} / \mathbf{m l}$ & Extract 150 $\boldsymbol{\mu g} / \mathbf{m l}$ & Standard 10 $\boldsymbol{\mu g} / \mathbf{m l}$ \\
\hline DPPH & $67 \pm 0.18$ & $77 \pm 0.16$ & $87 \pm 0.31$ & $92 \pm 0.10$ \\
\hline Superoxide & $46 \pm 0.24$ & $46 \pm .21$ & $57 \pm 0.18$ & $68 \pm 0.15$ \\
\hline Nitric Oxide & $68 \pm 0.31$ & $73 \pm .24$ & $77 \pm 0.17$ & $80 \pm 0.11$ \\
\hline Hydrogen Peroxide & $40 \pm 0.25$ & $42 \pm 0.22$ & $60 \pm 0.21$ & $67 \pm 0.16$ \\
\hline
\end{tabular}

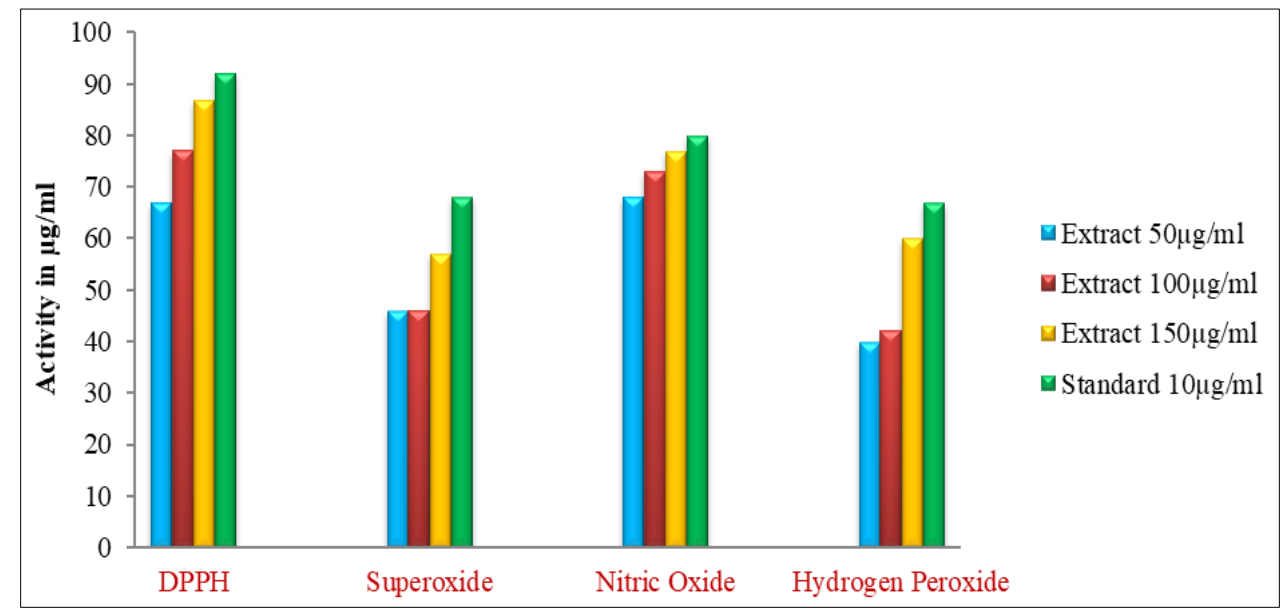

Fig 7: Anti oxidant activity of Gymnema sylvestre

Table 8: Anti oxidant activity of Santalum album (All values in this table represent the mean \pm SD ( $n=6$ )

\begin{tabular}{|c|c|c|c|c|}
\hline Santalum album & Extract 50 $\boldsymbol{\mu g} / \mathbf{m l}$ & Extract 100 $\boldsymbol{\mu g} / \mathbf{m l}$ & Extract 150 $\boldsymbol{\mu g} / \mathbf{m l}$ & Standard 10 $\boldsymbol{\mu g} / \mathbf{m l}$ \\
\hline DPPH & $74 \pm 0.11$ & $76 \pm 0.25$ & $85 \pm 0.25$ & $92 \pm 0.09$ \\
\hline Superoxide & $42 \pm 0.21$ & $44 \pm 26$ & $46 \pm 0.27$ & $68 \pm 0.11$ \\
\hline Nitric Oxide & $65 \pm 0.24$ & $70 \pm 0.29$ & $74 \pm 0.31$ & $80 \pm 0.15$ \\
\hline Hydrogen Peroxide & $37 \pm 0.19$ & $39 \pm 0.18$ & $57 \pm 0.34$ & $67 \pm 0.12$ \\
\hline
\end{tabular}

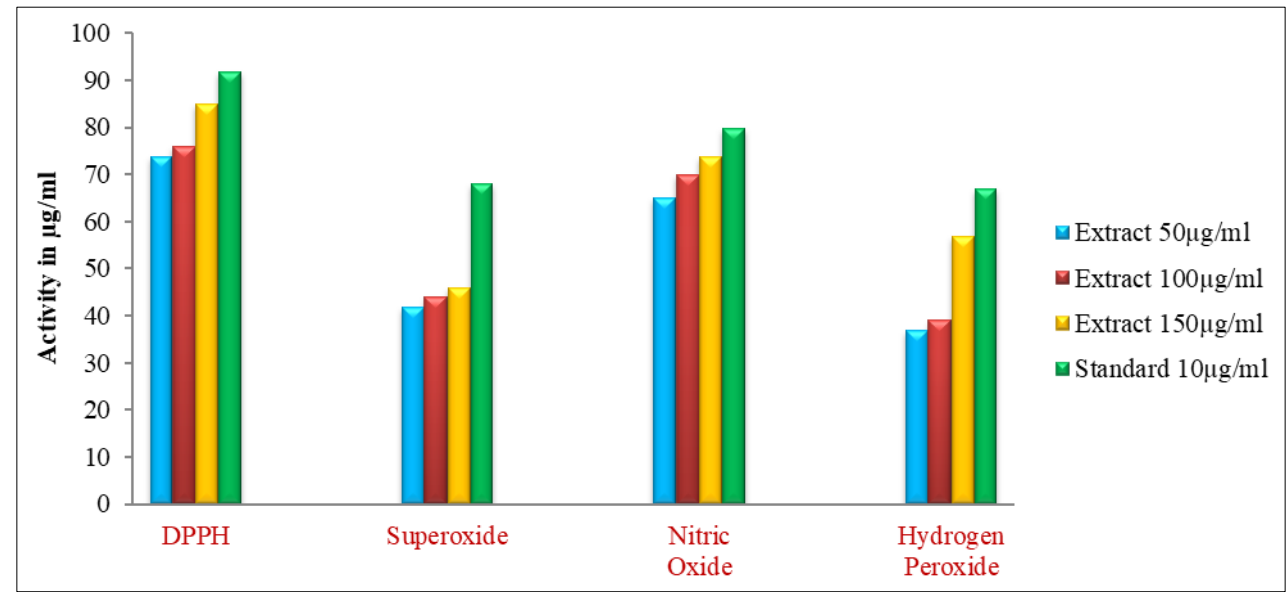

Fig 8: Anti oxidant activity of Santalum album

The DPPH scavenging activity of selected plant extracts reveals anti oxidant activity of the leaf extracts of Aegle marmelos, Butea monosperma, Commifora wighti, Holostemma ada-kodien, Decalepis hamiltonii, Gloriosa superba, Gymnema sylvestre Santalum album exhibited good scavenging activity at all tested concentrations (ascorbic acid of $10 \mu \mathrm{g} / \mathrm{mL}$ was used as standard).

\section{Conclusion}

The plants leaf extracts may be considered as a drug candidate, but requires further confirmation and safety and efficacy must be taken into account and there is a need to study the role of each individual components activity. Identification and isolation of individual phytochemical components in the extracts also has to be done for further investigations.

There is a need to popularize the cultivation of Medicinal plants with the necessary packages of practices. Further pharmacological investigations are necessary.

\section{References}

1. UNESCO Culture and Health, orientation-Texts world Decade for cultural Development. Document CLT/DEC/PRO, Paris, France. 1998, 129.

2. Cowan MM. Plant Products as Antimicrobial Agents. Clinical Microbiology Reviews. 1999;12:564-582.

3. Adesokan AA, Akanji MA, Yakubu MT. Anti bacterial potential; of aqueous extracts of Enantia chlorantha 
stem bark. African Journal Pmtechnology. 2008;6(22):2502-2505.

4. Nascimento F, Locatelli, Juliana, Freitas C, Silva L. Antibacterial activity of plant extracts and phytochemicals on antibiotic-resistant bacteria. Brazilian Journal of Microbiology. 2000;31(4):247-256.

5. Halliwell B, Gutteridge JMC, Cross CE. Free radicals, antioxidants and human diseases: where are we now? J. Lab. Clin. Med. 1994;119(6):598-620.

6. Ames BN, Shigenaga MK, Hagen TM. Oxidants, antioxidants, and the degenerative diseases of aging. Proc Natl Acad Sci U S A. 1993;90(17):7915-7922.

7. Deepa Babu, Prema Gurumurthy, Sai Krishna Borra, Cherian KM. Anti oxidant and free radical scavenging activity of triphala determined by using different in vitro models. Journal of medicinal plants research, 2013;7(39):2898-2905.

8. Asha Devi S, Deepak Ganjewala. Antioxidant Activities of Methanolic Extracts of Sweet-Flag (Acorus calamus) Leaves and Rhizomes, Journal of Herbs, Spices \& Medicinal Plants. 2011;17(1):1-11. 